\title{
Uso de Material Didático sobre Embriologia do Sistema Nervoso: Avaliação dos Estudantes
}

\author{
Use of Teaching Material About Nervous \\ System Embryology: a Students' Evaluation
}

Mariana Sampaio de Oliveira Mariana Nassif Kerbauy II

Camila Nassif Martins Ferreira ${ }^{I I I}$ Lucas José Vaz Schiavão

Rodrigo Franzoso Almeida de Andrade ${ }^{I}$ Maria Angélica Spadella

\section{PALAVRAS-CHAVE: \\ - Embriologia. \\ - Educação Médica. \\ - Materiais de Ensino.}

Recebido em: 20/04/2011

Aprovado em: 27/12/2011

REVISTA BRASILEIRA DE EDUCAÇ̃̃O MÉDICA
I Universidade Estadual de Campinas, Campinas, SP, Brasil.

"Universidade Federal de São Paulo, São Paulo, SP, Brasil.

III Faculdade de Medicina de Marília, Marília, SP, Brasil.

\section{RESUMO}

A Embriologia Humana é de extrema importância na formação de profissionais de saúde, porém seu estudo, muitas vezes, é considerado desestimulante, decorativo e sem significado prático para muitos estudantes, tornando-se pouco efetivo. Este trabalho objetivou produzir material didático interativo com modelos embrionários representativos do desenvolvimento embrionário do sistema nervoso. Para avaliar de forma qualitativa a real efetividade e capacidade de facilitar o processo de ensino-aprendizagem no contexto da Aprendizagem Baseada em Problemas, o material foi aplicado aos estudantes da primeira série de Medicina e Enfermagem da Faculdade de Medicina de Marília. Os estudantes consideraram que o material contribuiu para o entendimento do tema e facilitou a visualização dos eventos embrionários, além de despertar o interesse pelo estudo da disciplina. O material serviu como recurso para sedimentar o conhecimento e suscitou nos estudantes a integração dos conhecimentos com outras disciplinas. Em termos qualitativos, a análise dos questionários dos estudantes indicou que o material didático produzido foi efetivo na aprendizagem e funcionou como recurso na aprendizagem autodirigida, favorecendo a diversificação de fontes de busca e sendo complementar a livros-texto e outros materiais teóricos.

Human embryology is an extremely important part of training health professionals, but its study is often considered boring, decorative and without practical significance for many students, making it ineffective. This study aimed to produce interactive teaching material with embryonic models representing the embryonic development of the nervous system. To qualitatively evaluate the real effectiveness and ability to facilitate the teaching-learning process in the context of problem-based learning, the material was applied to first-year medicine and nursing students. The students felt that the material contributed to a better understanding of the topic and enabled visualization of embryonic events, as well as arousing interest in studying the subject. The material served to establish understanding and inspire the students to integrate the knowledge with other disciplines. Thus, in qualitative terms, analysis of the student questionnaires indicated that the material produced was effective for learning and worked as a resource in self-directed learning, promoting the diversification of search sources and being complementary to textbooks and other theoretical materials. 


\section{INTRODUÇÃO}

A compreensão do desenvolvimento pré-natal humano é de extrema importância na formação de profissionais de saúde, uma vez que torna possível a interpretação lógica das estruturas anatômicas presentes no adulto e sua correlação com as más-formações congênitas ${ }^{1}$. Apesar deste conhecimento ser fundamental para a integração com a prática clínica, observa-se, frequentemente, que o estudo de determinados conteúdos embriológicos é árduo, desestimulante, pouco prazeroso e, muitas vezes, nada efetivo.

Uma das limitações ao estudo da Embriologia Humana é a dificuldade, por parte dos acadêmicos, de visualização espacial das estruturas embrionárias e dos processos dinâmicos que ocorrem ao longo do desenvolvimento. Essa dificuldade se acentua devido à predominância de recursos didáticos não interativos sobre o tema e, também, ao fato de este estudo se pautar basicamente em livros-texto, que muitas vezes introduzem os processos do desenvolvimento de modo superficial e esquemático, não suficientemente de acordo com a realidade. Kramer e Soley ${ }^{2}$ reforçam estes aspectos ao apontarem em seu estudo que os estudantes do curso médico indicaram que a dificuldade em reter conhecimentos na área de Embriologia se baseia na incapacidade de visualizar, entender e compreender a sequência de eventos que caracteriza o processo de desenvolvimento embriológico, particularmente aquele em três dimensões. Segundo os mesmos autores, informações que não são entendidas ou visualizadas, mas decoradas, não constituem um aprendizado a longo prazo, e, quando os estudantes iniciam a prática clínica, encontram grande dificuldade em recordar aquilo que apenas decoraram.

Ainda na área da Embriologia Humana, Schleich e colaboradores ${ }^{3}$ destacam que o estudo desta disciplina, geralmente, é feito com rascunhos e desenhos em duas dimensões, que fornecem uma impressão apenas parcial da geometria dos eventos/objetos ilustrados. Além disso, a dinâmica da evolução estrutural é feita por meio de uma limitada sequência de imagens estáticas.

Pelas exigências atuais do processo de ensino-aprendizagem da Embriologia Humana e de sua importância prática na compreensão do desenvolvimento normal e das causas das variações da estrutura humana necessária ao profissional de saúde, recomenda-se o uso de diferentes abordagens e recursos didáticos na exploração deste tema, incentivando o estudante a sedimentar os conhecimentos necessários desta área morfológica, além de estimular seu interesse ${ }^{4}$. Embora não especificamente na área de Embriologia, mas considerando o processo de ensino-aprendizagem, Moreira ${ }^{5}$ cita a não centralidade do livro-texto e o uso de documentos, artigos e outros materiais educativos, como contos, poesias, crônicas, relatos e obras de arte, como maneiras de facilitar a aprendizagem significativa crítica. Assim, surge a necessidade de produzir métodos e materiais didáticos inovadores e desafiadores, a fim de tornar o estudo da Embriologia Humana mais consistente e interessante.

Considerando a proposta pedagógica dos métodos ativos de aprendizagem, a abordagem da Embriologia Humana se torna ainda mais delicada, na medida em que os estudantes devem exercer o processo de aprendizagem autodirigida, como destacado por Williams e $\mathrm{Lau}^{6}$, que afirmam que a reforma curricular nas escolas médicas em todo o mundo tem dado ênfase à aprendizagem independente e ao desenvolvimento de habilidades pessoais.

O emprego de recursos didáticos inovadores no processo de ensino-aprendizagem vai ao encontro da concepção pedagógica dos métodos ativos de aprendizagem, como no caso da Aprendizagem Baseada em Problemas (ABP). Neste contexto, a Faculdade de Medicina de Marília (Famema) foi uma das primeiras faculdades nacionais que promoveu uma significativa reforma curricular nos cursos de Medicina e Enfermagem a partir de 1997 e 1998, respectivamente. Nesta nova proposta pedagógica, o processo de ensino-aprendizagem passou a ser centrado no estudante, baseado em problemas e orientado para a comunidade ${ }^{7}$. Com o processo de avaliação permanente sobre o desenvolvimento curricular dos cursos de Medicina e Enfermagem da Famema, realizou-se, em 2003, nova mudança curricular com a implementação do currículo integrado e orientado por competência, para desenvolver um ensino contextualizado e proporcionar aos estudantes uma aprendizagem significativa ${ }^{8}$. No modelo da ABP, o estudante é direcionado para o desenvolvimento da capacidade de construir ativamente sua aprendizagem, de participar da exploração de problemas de saúde-doença, articulando seus conhecimentos prévios, de construir objetivos de aprendizagem para estudo, de buscar informações, além de analisar, discutir, criticar, integrar e aplicar o conhecimento em diversas áreas básico-clínicas.

Entre os objetivos de aprendizagem trabalhados pelos estudantes dos cursos de Medicina e Enfermagem da Famema, estão os pertinentes ao desenvolvimento embrionário do sistema nervoso. $\mathrm{O}$ aprendizado dos processos embrionários acerca deste sistema requer dos estudantes uma ampla noção espacial das estruturas envolvidas na formação da placa neural e do tubo neural, na diferenciação das vesículas encefálicas primárias e secundárias, além de exigir uma comparação anatômica com as estruturas que constituem o sistema nervoso no organismo adulto. Contudo, observa-se na prática didática que os estudantes apresentam dificuldade de imaginar um objeto em três dimensões, não compreendendo os processos di- 
nâmicos que ocorrem durante o desenvolvimento do sistema nervoso. Esta dificuldade de captar a dimensão espacial das modificações temporais e de desenvolvimento torna a aprendizagem pouco ou nada compreensível ${ }^{9,10}$.

Desta forma, a elaboração e a produção de materiais didáticos que atendam às necessidades dos estudantes em seu processo de aprender a aprender o desenvolvimento embrionário humano, procurando envolvê-los em sua aprendizagem, visam diminuir cada vez mais suas limitações, potencializando suas capacidades e fortalecendo a análise crítica dos conceitos trabalhados.

Neste contexto de incentivo ao estudo da Embriologia Humana, o presente trabalho teve como objetivo a construção de material didático interativo sobre o desenvolvimento embrionário do sistema nervoso e a avaliação de sua efetividade e capacidade de facilitar o processo de ensino-aprendizagem no modelo da Aprendizagem Baseada em Problemas. Espera-se que o recurso didático produzido facilite o estudo dos processos embriológicos envolvidos na formação do referido sistema e promova sua aprendizagem efetiva, contribuindo também para diversificar as fontes de estudo e estimular a aprendizagem autodirigida.

\section{Percurso Metodológico}

O presente estudo está de acordo com as diretrizes e normas regulamentadoras de pesquisa envolvendo seres humanos, de acordo com a Resolução 196/96, do Conselho Nacional de Saúde, sendo apreciado e aprovado pelo Comitê de Ética em Pesquisa da Famema, sob o protocolo de estudo no 209/08.

Inicialmente foi realizado um estudo detalhado sobre o tema proposto, visando à definição da estratégia de ensino do material didático e das fases do desenvolvimento do sistema nervoso que seriam contempladas, dando ênfase à visualização do desenvolvimento do encéfalo, envolvendo a formação da placa neural e do tubo neural, à diferenciação das vesículas encefálicas primárias e secundárias, à ocorrência das flexuras encefálicas e à comparação anatômica com as estruturas que compõem o encéfalo adulto.

A produção do material didático consistiu na utilização de um painel de chapa galvanizada emoldurado, no qual foram fixadas, por meio de ímãs, 12 placas de madeira MDF com modelos em alto-relevo de embriões, exibindo seis fases de diferenciação do encéfalo (Figura 1a). Estas fases de desenvolvimento compreenderam, aproximadamente, as seguintes idades dos embriões: 18 dias, 22 dias, 5 semanas, 8 semanas, 10 semanas e 12 semanas. Nos modelos em alto-relevo, as estruturas encefálicas do embrião foram confeccionadas com porcelana fria (massa de biscuit), enquanto o corpo e a cabeça do embrião foram produzidos com placa de EVA. Cada estrutura do encéfalo embrionário foi representada em cor diferente, e suas derivadas com a mistura das respectivas cores (Figuras 1c-1h). As placas de madeira foram construídas de forma a apresentarem mobilidade para permitir sua montagem no painel galvanizado de acordo com as fases de diferenciação do encéfalo. Figuras em microscopia eletrônica de varredura representativas da evolução do encéfalo e uma figura esquemática da anatomia do encéfalo adulto foram utilizadas como plano de fundo, aplicadas em papel adesivo no painel galvanizado (Figura 1b).

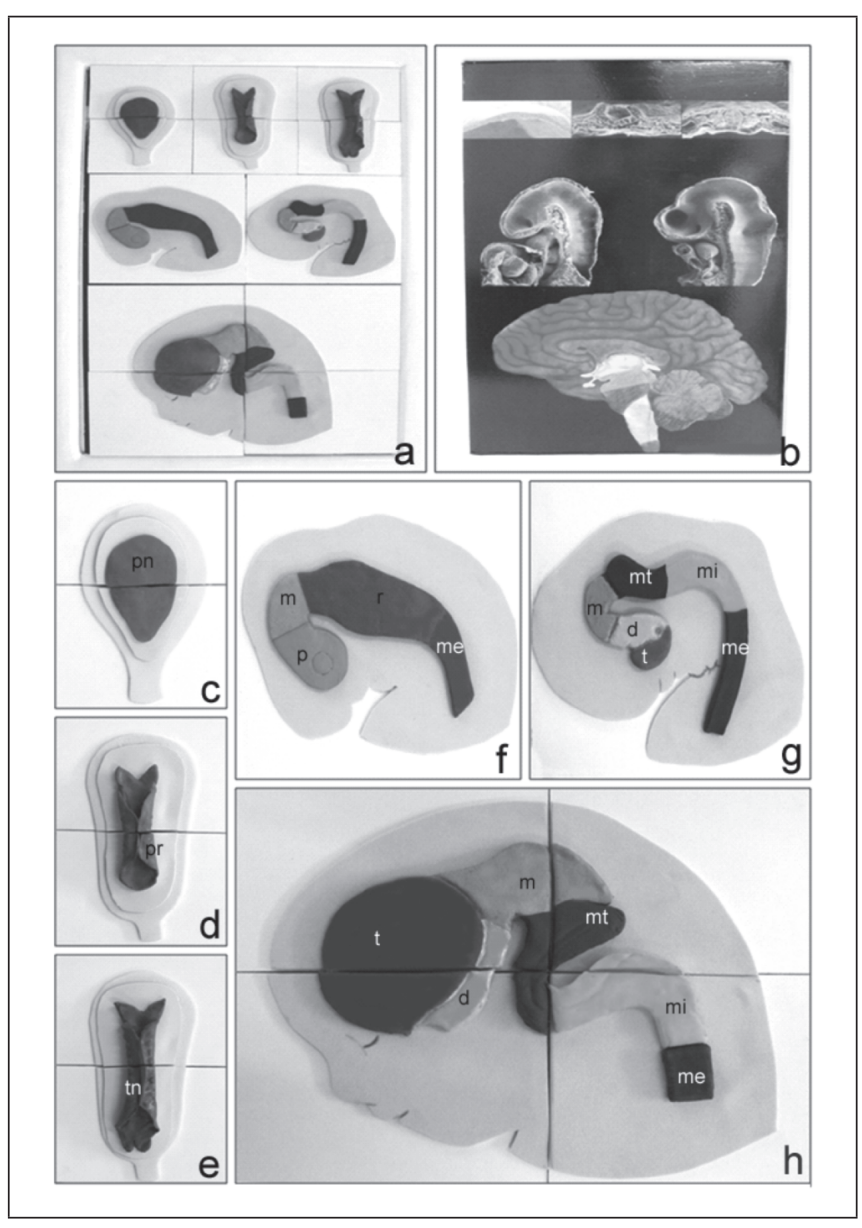

Figura 1: Fotografias do material didático produzido. (a) Painel emoldurado com placas de madeira fixadas, contendo os modelos embrionários em diferentes fases de desenvolvimento do sistema nervoso central; (b) Painel sem as placas de madeira, exibindo o plano de fundo com imagens do sistema nervoso primitivo em microscopia eletrônica de varredura e um esquema do encéfalo adulto; (c a e) Detalhe da formação do tubo neural: placa neural (c), pregas neurais em fusão (d) e tubo neural, apresentando as aberturas anterior (neuróporo anterior) e posterior (neuróporo posterior) (e); (f e g) Detalhe da derivação das vesículas encefálicas primárias (f) em vesículas encefálicas secundárias (g); (h) Vesículas encefálicas secundárias em diferenciação. Abreviaturas: $\mathrm{d}$ = diencéfalo, $\mathrm{m}=$ mesencéfalo, $\mathrm{me}=$ medula espinhal, $\mathrm{mi}=$ mielencéfalo, $\mathrm{mt}=$ metencéfalo, $\mathrm{p}=$ prosencéfalo, $\mathrm{pn}=$ placa neural, $\mathrm{pr}=$ pregas neurais, $\mathrm{r}=$ rombencéfalo, $\mathrm{t}$ $=$ telencéfalo, $\mathrm{t} \mathrm{n}=$ tubo neural 
Como estratégia de aplicação do material didático, foi desenvolvido um roteiro de estudo, de forma a possibilitar aos estudantes a utilização do recurso também nos casos em que não há supervisão docente, estimulando o processo de autoaprendizagem. O conteúdo deste roteiro consistiu em instruções para utilizar o material didático e em questões de aprendizagem acerca dos diferentes estágios de desenvolvimento do sistema nervoso, para serem respondidas pelos estudantes (Quadro 1). Ao término da utilização, para que o estudante pudesse reconhecer suas lacunas de aprendizagem e definir seu estudo posterior, visando a um processo formativo, foi elaborado um gabarito com o mínimo esperado para as respostas às questões do roteiro e as legendas das figuras do plano de fundo do painel.

\section{QUADRO 1}

Roteiro de Estudo Apresentado aos Estudantes Participantes durante a aplIcação do Material Didático

\section{a) Instruções de uso do material didático}

Realize a montagem do painel, fixando as placas de madeira com modelos embrionários em alto-relevo, nos locais correspondentes às imagens de microscopia eletrônica de varredura (MEV) e ao esquema anatômico do encéfalo adulto, estabelecendo uma sequência lógica de desenvolvimento do sistema nervoso central (SNC).

\section{b) Questões de aprendizagem}

Analise e responda as questões a seguir e, em seguida, anote suas respostas em um papel.

Elabore novas questões de aprendizagem segundo as necessidades do grupo.

1. Identifique e nomeie, nos modelos em alto-relevo, os folhetos embrionários e determine em qual estágio de desenvolvimento se encontra o SNC, principalmente o encéfalo.

2. Relacione os estágios de formação do SNC com a cronologia de seu desenvolvimento, considerando os modelos embrionários em alto-relevo e as imagens em MEV do plano de fundo.

3. Identifique e nomeie as flexuras encefálicas que ocorrem durante a formação do SNC, determinando em que fase do desenvolvimento elas acontecem, e delimite as regiões do encéfalo primitivo que sofrem curvatura.

4. Relacione as vesículas encefálicas primárias com suas derivadas secundárias, nomeando cada uma delas, e correlacione com a cor dos modelos em alto-relevo presentes nas placas.

5. A partir do esquema do encéfalo adulto presente no plano de fundo, identifique e nomeie suas regiões anatômicas, mencionando suas respectivas cores.

6. Considerando ainda o esquema do encéfalo adulto, relacione cada uma das regiões, delimitadas por cores diferentes, com a respectiva vesícula encefálica secundária que a originou.

7. Compare suas respostas com o gabarito apresentado, avaliando suas lacunas de aprendizagem.
Para avaliar a efetividade do material na aprendizagem, realizou-se atividade extracurricular com os estudantes da primeira série dos cursos de Medicina e Enfermagem da Famema, no ano de 2009, após abordagem do tema em atividades curriculares (sessões de tutoria). Esta série foi escolhida como campo de estudo, pois contempla na grade curricular vários objetivos acerca do desenvolvimento embrionário do sistema nervoso. A participação dos estudantes se deu de forma voluntária, sendo que todos os estudantes da série foram convidados a participar. Antes do preenchimento da avaliação, foi solicitado a cada participante que assinasse um Termo de Consentimento Livre e Esclarecido, garantindo a livre adesão ao estudo, sigilo quanto às informações prestadas, direito de deixar a pesquisa a qualquer momento, esclarecimento quanto aos objetivos do estudo, forma como se daria a participação dos estudantes e nome dos pesquisadores responsáveis.

$\mathrm{Na}$ atividade de aplicação do material didático, os estudantes foram distribuídos em grupos de quatro componentes, sendo entregue a cada grupo o painel sem as placas de madeira fixadas, as quais estavam "soltas" e não organizadas em uma sequência lógica, e também o roteiro de estudo. No início da atividade, foi realizada uma breve apresentação do material didático produzido, e os estudantes foram orientados a desenvolver a atividade com base no roteiro de estudo. Também foram orientados a trabalhar com o material didático sem supervisão docente, com o objetivo de esta conduta não interferir na avaliação do material didático quanto à sua utilização como recurso didático de autoaprendizagem. Contudo, abriu-se a possibilidade de consultas à docente da disciplina Embriologia Humana da Famema ou aos estudantes autores do presente trabalho para o esclarecimento de dúvidas pontuais, não sendo fornecidas mais explicações ou detalhamentos sobre o desenvolvimento embrionário do sistema nervoso.

Durante a aplicação, os estudantes realizaram a montagem do painel, fixando as placas de madeira com os modelos em alto-relevo dos embriões nos locais correspondentes às imagens presentes no plano de fundo do painel, devendo estabelecer uma sequência lógica de desenvolvimento do sistema nervoso central. Após esta etapa, os estudantes responderam as questões do roteiro de estudo para saberem o nível de conhecimento e aprofundamento sobre o assunto.

Após o período de montagem, estudo e análise do painel e das placas, com o tempo definido pelos próprios grupos de estudantes segundo suas necessidades, foi solicitada a avaliação do material didático utilizado, por meio do preenchimento de um questionário. Composto por quatro questões discursivas, esse questionário visava à análise qualitativa do material, para investigar sua validade e importância no que se refere à es- 
tratégia de autoaprendizagem e suas reais potencialidades no aprendizado da embriogênese do sistema nervoso.

A avaliação do material didático contou com as seguintes questões norteadoras: Qual a sua opinião sobre o material didático utilizado? Descreva o que você considerou favorável e/ou desfavorável durante a utilização do material didático. O material didático utilizado serve como recurso de autoaprendizagem ou necessita de supervisão? Justifique. Após a utilização do material, em que medida e de que forma ele contribuiu em sua aprendizagem?

As informações coletadas por meio do instrumento de avaliação foram analisadas segundo a técnica de análise de conteúdo na modalidade temática proposta por Bardin ${ }^{11}$, que consistiu em leituras detalhadas dos questionários, com o objetivo de identificar palavras e conjuntos de palavras que tinham sentido para a pesquisa. Posteriormente, estas informações foram tratadas por meio da classificação em categorias ou temas de dados que tinham semelhança quanto ao critério sintático ou semântico ${ }^{12}$. A análise final consistiu na interpretação dos resultados obtidos com auxílio da fundamentação teórica de Deslandes e colaboradores ${ }^{13}$ e Minayo $^{14}$. As categorias de análise foram não excludentes em cada resposta, vista a variabilidade de temas encontrados nas questões.

Para garantir o sigilo dos dados preenchidos e o anonimato, cada estudante participante foi representado da seguinte forma: E1, E2, E3... En.

\section{APRESENTAÇÃO E DISCUSSÃO DOS RESULTADOS}

Dos 120 estudantes da primeira série dos cursos de Medicina e Enfermagem da Famema convidados para compor a amostra da presente pesquisa, 69 (57,5\%) aceitaram participar da atividade de aplicação do material didático produzido e responder ao instrumento de avaliação do mesmo. Em geral, os participantes deram andamento ao processo sem a necessidade de supervisão, conseguindo realizar a montagem e interpretação das placas e dos modelos embrionários, sendo capazes também de responder às questões de aprendizagem propostas no roteiro de estudo.

Ao se analisarem os resultados, tomando-se como parâmetro as respostas dos estudantes que preencheram o instrumento de avaliação, foi possível definir cinco categorias temáticas, descritas a seguir

\section{O Material Didático como Incentivador do Estudo,} Favorecendo o Aprendizado da Embriologia Humana

Considerando-se a opinião sobre o material didático utilizado, os estudantes mencionaram que ele contribuiu para o enten- dimento do tema e destacaram a visualização facilitada dos eventos embrionários devido à característica estrutural dos modelos apresentados, como se evidencia nestas respostas:

O material é muito bom para a construção de nossa aprendizagem, ajudando-nos a visualizar as imagens do desenvolvimento embrionário, obtendo, assim, maior compreensão e entendimento. (E7)

[...] ajuda a guardar e reconhecer as partes do desenvolvimento do sistema nervoso. (E25)

Facilitador do entendimento estrutural e posicionamento anatômico. (E34)

O material ajudou muito no processo de ensino-aprendizagem, fazendo com que tirássemos nossas dúvidas [...] facilitou a compreensão. (E41)

Apontou-se também o fato de o material despertar o interesse pelo estudo da disciplina em questão:

Estou mais interessada no processo de formação do tubo e do sistema nervoso central e comecei a entender um pouco mais sua formação. (E5)

[...] além de ser esclarecedor, desperta nosso interesse em Embriologia. (E26)

[...] serviu para aprender muito sobre Embriologia do sistema nervoso central. (E45)

Esta característica incentivadora do material corrobora o que foi observado por Schleich e colaboradores ${ }^{3}$ ao avaliarem material didático 3D sobre os processos embriológicos da septação cardíaca, destacando que a proposta de utilização de recursos didáticos diferenciados estimula a motivação dos estudantes para aprender. Também possibilita ao estudante formar imagens mentais mais próximas das estruturas embrionárias reais das fases do desenvolvimento embrionário ${ }^{15}$.

Neste contexto, em que o estudante deve ser estimulado no processo de ensino-aprendizagem, infere-se que o recurso didático serviu como estratégia de estudo para a Embriologia Humana, matéria básica apontada como difícil de ser trabalhada unicamente em sessões de tutoria, como demonstrou estudo realizado por Gomes e colaboradores ${ }^{16}$ com egressos do curso de Medicina que tiveram sua formação ancorada no método ABP. Além disto, este estudo também destacou a dificuldade dos estudantes de integrar os conteúdos das disciplinas básicas com a clínica. 
Dessa forma, o recurso didático desenvolvido se apresenta como uma alternativa inovadora para trabalhar estes conteúdos, visto que, no presente estudo, os participantes mencionaram que ele pode servir como recurso para fixar a matéria e sedimentar o conhecimento, como se percebe nas falas seguintes:

O material contribui bastante para meu entendimento, por dar uma visão melhor do assunto. (E29)

Contribuiu para fixação, entendimento das fases e clarear melhor o que eu tinha estudado no livro de Embriologia. (E36)

[...] proporcionou a sedimentação do conhecimento. (E52)

[...] o material foi bom para concretizar o que foi lido, sedimentando novas informações. (E48)

A estratégia de implementação de recursos didáticos desafiadores para os estudantes da área da saúde é relevante ao se entender que a dificuldade de constatação da importância da Embriologia e de outras disciplinas básicas é atribuída, muitas vezes, ao fato de serem encaradas como decorativas e sem significado para muitos estudantes. O uso de modelos didáticos macroscópicos pode minimizar a dificuldade de abstração dos estudantes iniciantes no conhecimento embriológico, pois promove a aproximação do discente do que está sendo estudado, possibilitando a ele fazer comparações ${ }^{17}$

\section{Promotor da Visão Dinâmica e Tridimensional do Desenvolvimento com a Integração de Disciplinas}

Quanto à presença da figura esquemática da anatomia do encéfalo adulto no plano de fundo do painel, relacionada com as vesículas encefálicas embrionárias que lhe deram origem e à apresentação de imagens, em microscopia eletrônica de varredura, das estruturas encefálicas embrionárias em diferentes estágios de diferenciação e cortes, os estudantes mencionaram que estas imagens facilitaram a interpretação da sequência lógica de desenvolvimento do sistema nervoso, além de possilitarem a integração dos conhecimentos com outras disciplinas morfológicas, principalmente a Anatomia:

A prancha foi um ponto favorável, pois fornece uma imagem de microscopia de varredura mais bem compreendida do que os esquemas de livros. (E68)

As imagens coloridas e o esquema de montagem cronológica são favoráveis. (E38)
O material contribuiu para a percepção de que, além de estudar Embriologia, devo estudar Anatomia também, relacionando os dois assuntos durante o estudo. (E11)

[...] ajudou a perceber a origem das vesículas do encéfalo, bem como sua posterior diferenciação. (E66)

[ajudou a] distinguir as estruturas do encéfalo e localizar as partes do sistema nervoso central. (E64)

Os estudantes não estão acostumados com recursos didáticos diferentes e interativos na área de Embriologia Humana. A maioria deles busca informações desta disciplina em livros-texto, que apresentam figuras planas, muitas vezes até sem cores. Isto dificulta a visualização e a compreensão dos processos dinâmicos e tridimensionais do desenvolvimento tão importantes e necessários ao real entendimento e fixação do conteúdo. Rodrigues e colaboradores ${ }^{18}$ também discutem a dificuldade no aprendizado pela falta de recursos adequados, como modelos tridimensionais que representem as diversas fases do desenvolvimento. A complexidade presente no estudo da Embriologia está justamente na necessidade da interpretação da morfogênese dessa forma tridimensional ${ }^{19}$. Além disso, os estudos do desenvolvimento, muitas vezes, são voltados para aulas teóricas, resultando numa forma de abordagem desestimulante ao estudante, o que torna o aprendizado difícil e pouco efetivo.

Contrariamente ao contexto apresentado, o material didático desenvolvido surge como alternativa a esse modelo, buscando tornar o estudo mais atraente, menos cansativo e mais significativo, na medida em que possibilitou ao estudante o entendimento dos processos dinâmicos que envolvem o desenvolvimento do sistema nervoso, de maneira tridimensional. Além disto, estimulou a percepção dos estudantes para outros conteúdos que eles também precisam estudar para que obtenham a real compreensão do que está sendo estudado, favorecendo, assim, a inter-relação com outras disciplinas.

\section{Estrutura do Material Didático e sua Estratégia de uso como Facilitadores da Aprendizagem}

A partir dos apontamentos feitos pelos estudantes sobre as características físicas dos modelos embrionários constituintes do material didático, destacou-se a visualização facilitada dos eventos embrionários devido ao fato de o material ser ilustrativo, colorido e em alto-relevo, além de possuir característica tridimensional, como se pode perceber nas seguintes respostas:

[...] a montagem $e$ as cores utilizadas no material ajudam muito no aprendizado [...]. (E32) 
Contribuiu muito, foi com certeza favorável para a aprendizagem, e o fato de poder ter as peças na mão "em 3D" foi ótimo. (E45)

Um ponto bastante favorável [...] é o esquema de cores utilizado, pois auxilia na visualização da sequência de desenvolvimento do encéfalo. (E46)

[...] esclareceu vários pontos do desenvolvimento neural do embrião, ainda mais com a didática das cores e do relevo.

Estas respostas revelam que as características estruturais do material foram consideradas muito marcantes e significativas para os estudantes, visto que essas respostas surgiram a partir do questionamento geral sobre a opinião deles em relação ao recurso didático utilizado.

Quando questionados especificamente sobre o que consideraram aspectos favoráveis na utilização do material, novamente esses fatores apontados surgem nas respostas. Os estudantes destacaram o favorecimento da visualização tridimensional, o esquema de cores e a característica em alto-relevo dos modelos, como exemplificado nas falas:

Favorável: desenho colorido e em alto-relevo; proporciona uma visão diferenciada dos livros comuns. (E31)

Muito favorável o esquema de cores, que se continuam ao longo do desenvolvimento, permitindo uma rápida associação. (E47)

Contribuiu na visualização mais clara dos processos de forma tridimensional. (E51)

Também mencionaram a estruturação do material na forma de peças montáveis ("quebra-cabeça"), o que facilitou o entendimento do assunto:

Favorável em relação ao fácil entendimento, tanto as camadas em alto-relevo como o fácil manejo. (E64)

O fato de instigar o raciocínio, por causa da montagem das peças, ajudou a fortalecer, a dar segurança na compreensão das regiões. (E3)

O material facilitou a compreensão; visualizando e montando as etapas ficou mais fácil. (E41)

Achei muito interessante tanto a descoberta de montar o quebra-cabeça, quanto entender, comparar e responder as questões. (E12)

\section{O Material Didático como Recurso Educacional de Autoaprendizagem}

Considerando-se que a proposta do presente trabalho foi desenvolver um material didático que facilitasse o aprendizado do desenvolvimento embrionário do sistema nervoso, principalmente em cursos de graduação que utilizam o método $\mathrm{ABP}$, foi levantada a questão da necessidade de supervisão durante a utilização desse material, em contraposição ao questionamento se ele serve como ferramenta de autoaprendizagem. Nesse contexto, os participantes responderam que o objetivo da autoaprendizagem foi atingido plenamente, sendo que o roteiro de estudo apresentado favoreceu esta proposta, como evidenciado nas seguintes respostas:

Foi um bom recurso de autoaprendizagem, incentivando curiosidade e pesquisa. (E8)

Por se tratar de um recurso dinâmico, ele é de autoaprendizagem, onde o aluno, com um pouco de curiosidade e certo conhecimento, é capaz de aprender com muita qualidade. (E22)

O material didático utilizado serviu como recurso de autoaprendizagem, pois nos fez compreender melhor a matéria em estudo. (E43)

[...] serve como recurso de autoaprendizagem, pois favorece a identificação e visualização das partes do embrião. (E44)

Com o roteiro de perguntas fica fácil entender o objetivo da atividade, não se necessitando de supervisão. (E61)

Ainda nesta questão, os estudantes afirmaram que o material se qualifica ainda mais como instrumento de autoaprendizagem se houver conhecimento prévio do assunto e, consequentemente, facilitará o entendimento tanto do material didático quanto do livro-texto. Desta forma, a compreensão depende, em grande parte, do grau de aproximação entre os conhecimentos veiculados no texto/modelo e os conhecimentos armazenados na memória do leitor, que no caso é o estudante. Quanto mais estreita for essa relação e maior for o conhecimento partilhado entre o estudante e o conhecimento que deve ser aprendido, melhor será a compreensão. Desse modo, observamos que o processo de compreensão teve como base o conhecimento prévio:

O material serve como recurso de autoaprendizagem se hou ver o conhecimento teórico prévio por parte de quem o utiliza. (E11)

Pode ser utilizado como recurso de autoaprendizagem se o estudante já estudou previamente. (E2) 
Depende do quanto a pessoa sabe sobre o assunto. Quem não estudou precisa de muita supervisão, mas quem já tem conhecimento prévio não necessita de ajuda. (E25)

Observa-se, assim, que existiu uma inter-relação entre livro-texto e material didático utilizado, no sentido de que um complementou o outro, uma vez que o conhecimento adquirido pelos estudantes com a leitura e as discussões no grupo de tutoria foi resgatado, organizado e acrescido de informações quando utilizaram as placas dos modelos embrionários. De forma semelhante, as placas provocaram os mesmos processos em relação à leitura. Esta abordagem configura a proposta da Teoria da Aprendizagem Significativa de David Ausubel ${ }^{20}$, a qual postula que a partir dos conteúdos prévios que os estudantes possuem em sua estrutura cognitiva é que a aprendizagem pode ocorrer, uma vez que este conhecimento prévio deverá receber novos conteúdos que poderão modificar e dar outras significações a estes conhecimentos preexistentes ${ }^{21}$.

Tanto um bom processo de leitura quanto o trabalho com os modelos didáticos são processos ativos, incluindo predição, elaboração de hipóteses e previsões. O estudante observa os recursos visuais e gráficos para levantar uma série de hipóteses e construir representações mentais ${ }^{22}$. Desse modo, podemos propor que o material concreto e a leitura se articularam e funcionaram como recursos complementares para a elucidação de dúvidas e a construção dessas representações, permitindo um melhor processo de autoaprendizagem.

Portanto, para construir ativamente sua aprendizagem, o estudante necessita articular seus conhecimentos prévios com o estímulo proporcionado pela situação-problema selecionada para estudo, como se percebe na resposta seguinte:

No meu caso, [o material didático] não contribuiu muito, visto que eu ainda não tinha tido nenhuma aproximação com o tema. (E65)

A necessidade de supervisão durante a utilização do material didático também foi mencionada pelos estudantes participantes:

Durante o primeiro contato, acredito que necessita de supervisão. Nos contatos seguintes, o estudante pode exercer melhor o recurso de autoaprendizagem. (E20)

A supervisão complementa o entendimento. (E2)

Ajuda na autoaprendizagem, mas uma supervisão é sempre positiva para confirmar informações. (E48)

Esta necessidade de supervisão é compreensível e até mesmo esperada, considerando que os participantes da pes- quisa eram da primeira série dos cursos de Medicina e Enfermagem da Famema, que estavam vivenciando pela primeira vez o novo modelo pedagógico. Isto representa a visão internalizada do ensino tradicional em que o estudante acredita que deve atuar somente como receptor do conhecimento e não como construtor do próprio conhecimento, como preconizado pelo método ABP. Esta dificuldade representa um desafio docente frente ao estudante da primeira série, uma vez que demanda a construção de uma nova forma de aprender. Neste sentido, o material didático proposto buscou quebrar estes conceitos e princípios adquiridos pelas práticas tradicionais e demonstrar que qualquer conhecimento, mais do que aprendido pelo aluno, deve ser "construído" por ele em um processo altamente dinâmico, que depende da atividade mental do educando e que se desenvolve pela mobilização de seus esquemas de raciocínio ${ }^{23,24}$.

\section{O Uso do Material Didático Oportunizando a}

\section{Aprendizagem Ativa}

Quando interrogados a respeito da contribuição que o material pode trazer para a aprendizagem, os estudantes citaram a facilitação da visualização do desenvolvimento embrionário estudado no livro-texto, relacionada ao fato de o material ser concreto. Os alunos também mencionaram que o material didático serviu como recurso para esclarecimento do assunto, ajudou na aprendizagem e complementou o livro-texto, servindo como diversificação das fontes de estudo:

Consegui entender realmente o que eu havia lido. (E27)

Ele contribui para que o entendimento seja mais concreto e, assim, o conhecimento fique mais sedimentado. (E24)

Facilitou o estudo, pois mostrou as imagens estudadas nos livros de maneira concreta. (E21)

[...] exige do aluno uma capacidade de assimilação das imagens e suas conexões, interpretando e atribuindo a elas uma certa explicação.

É muito mais concreto e ajuda a entender os planos de visão. (E4)

Foi muito válido para diversificar minhas fontes de estudo. (E1)

Este fato revela um dos propósitos do desenvolvimento deste painel, que é o de complementar e facilitar o estudo, e não substituir o livro-texto ou outros recursos existentes. 
Outro padrão de resposta encontrado nessa questão foi a possibilidade de identificar lacunas de aprendizagem a partir da manipulação dos modelos embrionários do painel e direcionar o estudo do aluno aos pontos relevantes para o entendimento da matéria:

O material contribui na revelação de lacunas de estudo, tanto de Embriologia como de Anatomia. (E8)

Contribuiu para o esclarecimento das partes fundamentais, focando aquilo que é mais importante. (E3)

[...] me ajudou a focar os estudos, pois a Embriologia tem muita coisa [...]. (E2)

[...] ajudou a estudar a matéria que apenas com livros-texto fica mais difícil. (E38)

Como destacado pelos estudantes participantes, o material didático produzido foi efetivo na aprendizagem, favorecendo a diversificação de fontes de estudo, sendo complementar a livros-texto e a outros materiais teóricos, indo ao encontro da sua proposta idealizadora. Além disso, permitiu ao estudante reconhecer seus limites e fragilidades, para definição do grau de aprofundamento de seu estudo posterior.

\section{CONSIDERAÇÕES FINAIS}

O grande desafio educacional da atualidade, em que o volume de informações e os avanços técnico-científicos se propagam, é preparar as novas gerações para lidar com a construção diária de seu conhecimento, principalmente desenvolvendo habilidades, competências e valores necessários ao bom desempenho profissional, configurando-se o estudo da Embriologia Humana uma necessária disciplina instrumentalizadora do estudo das ciências ${ }^{25}$.

Este desafio está presente nas respostas dos estudantes participantes, que avaliaram positivamente o recurso didático produzido, uma vez que ele facilitou a aprendizagem estimulando, instigando e desenvolvendo o pensamento lógico. A utilização do material também permitiu melhor compreensão da embriologia do sistema nervoso central e a visualização facilitada das estruturas embrionárias, favorecendo o entendimento de processos dinâmicos deste desenvolvimento, que são difíceis de compreender apenas com a leitura de materiais teóricos.

Constatou-se que o material didático desenvolvido serve como "situação-problema", sendo capaz de desencadear uma dúvida e de gerar curiosidade. Além disto, o material estimulou a busca de informações necessárias, adicionais ou complementares sobre o assunto para depois analisá-lo, discuti-lo e aplicá-lo em diversas áreas do conhecimento, em consonância com a Aprendizagem Baseada em Problemas. Também favoreceu, de maneira particular, a educação problematizadora, que trabalha a construção de conhecimentos a partir da vivência de experiências, favorecendo a aprendizagem significativa.

\section{AGRADECIMENTOS}

Os autores agradecem aos estudantes da primeira série dos cursos de Medicina e Enfermagem da Faculdade de Medicina de Marília (Famema) a participação na presente pesquisa e também ao Prof. Dr. Osni Lázaro Pinheiro, da disciplina de Farmacologia da Famema, suas importantes contribuições ao manuscrito.

\section{REFERÊNCIAS}

1. O'Rahily R, Müller F. Embriologia e teratologia humanas. $3^{\mathrm{a}}$ ed. Rio de janeiro: Guanabara Koogan; 2005.

2. Kramer B, Soley JT. Medical students perception of problem topics in Anatomy. East African Med J. 2002;79(8):408-14.

3. Schleich J, Dillenseger JL, Houyel L, Almange C, Anderson RH. A new dynamic 3D virtual methodology for teaching the mechanics of atrial septation as seen in the human heart. Anat Sci Educ. 2009;2(2):69-77.

4. Souza RR. Algumas considerações sobre as abordagens construtivistas para a utilização de tecnologias na educação. Liinc em Revista. 2006;2(1):50-65.

5. Moreira MA. Aprendizagem significativa: da visão clássica à visão crítica. Conferência do V Encontro Internacional sobre Aprendizagem Significativa, Madri, Espanha, setembro 2006 e do I Encuentro Nacional sobre Enseñanza de la Matemática, Tandil, Argentina, abril 2007.

6. Willians G, Lau A. Reform of undergraduate medical teaching in the United Kingdom: a triumph of evangelism over common sense. BMJ. 2004;329:92-4.

7. Faculdade de Medicina de Marília. Projeto Famema 2000: consolidação. Marília: FAMEMA; 1998.

8. Faculdade de Medicina de Marília. Programa nacional de reorientação da formação profissional em saúde - Pró-Saúde. Marília:FAMEMA; 2005.

9. Moore KL, Persaud TVN. Embriologia Clínica. $8^{\text {a }}$ ed. Rio de Janeiro: Elsevier; 2008.

10. Rohen JW, Lütjen-Drecoll E. Embriologia Funcional. 2ª ed. Rio de Janeiro: Guanabara Koogan; 2005.

11. Bardin L. Análise de conteúdo. Lisboa: Ed. 70; 2003.

12. Oliveira E, Ens RT, Andrade DBSF, Mussis CR. Análise de conteúdo e pesquisa na área da educação. Rev Diálogo Educ. 2003;4(9):11-27. 
13. Deslandes SF, Gomes R, Minayo MCS. Pesquisa social: teoria, método e criatividade. 27ํㅡ ed. Petrópolis, RJ: Vozes; 2008

14. Minayo MCS. O desafio do conhecimento: pesquisa qualitativa em saúde. 9ª ed. São Paulo: Hucitec; 2006.

15. Freitas LAM, Barroso HFD, Rodrigues HG, Aversi-Ferreira TA. Construção de Modelos Embriológicos com material reciclável para uso didático. Biosci J. 2008;24(1):91-7.

16. Gomes R, Francisco AM, Tonhom SFR, Costa MCG, Hamamoto CG, Pinheiro OL, et al. A formação médica ancorada na aprendizagem baseada em problema: uma avaliação qualitativa. Interface Comun Saúde Educ. 2009;13(28):71-83.

17. Rogado J. A grandeza quantidade de material e sua unidade, o mol: algumas considerações sobre dificuldade de ensino e aprendizagem. Rev Cienc Educ. 2004;10(1):63-73.

18. Rodrigues ALM, Fiedler PT, Santos SHPD, Perotta B, Hirose TE, Oliveira SAD, et al. Embriologia prática: uma lição diferente. Arq Apadec. 2004;8(supl. 2):11.

19. Perotta B, Fiedler PT, Santos SHPD, Hirose TE, Rodrigues ALM, Oliveira SAD, et al. Demonstração prática do desenvolvimento pulmonar humano. Arq Apadec. 2004;8(Supl. 2):14.

20. Ausubel DP, Novak, JD, Hanesian H. Psicología educativa: un punto de vista cognoscitivo. México: Trillas; 1983.

21. Moreira MA. Conferência de encerramento do IV encontro internacional sobre aprendizagem significativa. Moragogi, AL, Brasil, 8 a 12 de setembro de 2003.
22. Trevisan EMC. Leitura e conhecimento prévio. Rev Letras. 1991:27-36.

23. Gonçalves EL. Pedagogia e didática: relações e aplicações no ensino médico. Rev Bras Educ Med. 2001;25:20-6.

24. Ertmer PA, Newry CJ. Behaviorism, cognitivism, constructivism: Comparing critical features from an instructional design perspective. Performance Improvement Quarterly. 1993;6(4):50-72.

25. Gil AC. Metodologia do ensino superior. São Paulo: Atlas; 1994.

\section{CONTRIBUIÇÃO DOS AUTORES}

Os autores participaram igualmente de todas as etapas de elaboração, execução e análise dos resultados deste trabalho.

\section{CONFLITO DE INTERESSES}

Declarou não haver.

\section{ENDEREÇO PARA CORRESPONDÊNCIA}

Maria Angélica Spadella

Faculdade de Medicina de Marília — Famema

Av. Monte Carmelo, 800 - Caixa Postal 2003

CEP 17519-030 - SP

E-mail: maspadella@gmail.com 